\title{
Master Production Scheduling and A Comparison of Material Requirements Planning and Cover-Time Planning
}

\author{
Anders Segerstedt \\ Industrial Logistics, IES, Luleå University of Technology, Sweden
}

\begin{abstract}
For a company's long-term profitability, most important processes are the way it starts parts of the manufacturing process before the customer order arrives and the way it determines and promises delivery quantities and times for the customer orders. In practical computer applications Material Requirement Planning and/or Reorder point systems are the base techniques mostly used. This article presents CoverTime Planning, a variant of a reorder point system. Cover-Time Planning (CTP) is developed with a forward-looking forecasted demand rate and the decision variable is "time", instead of "quantity" for an ordinary reorder-point system. MRP and CTP are introduced and compared through a numerical ex $\neg$ ample. MRP and CTP must treat practical "make-to-order"; therefore, this paper discuss available-to-prom $\neg$ ise, planning bills, and other help systems for practical applications of Master Production Scheduling. The paper presents how and why, in practice, a Master Production Scheduling system with an available-topromise function should be used and how this system should be designed. It is also here argued that a fully Enterprise Resource Planning (ERP) system cannot only be created by MRP, but also by CTP.
\end{abstract}

\section{Keywords:}

Master Production Scheduling, Material Requirements Planning, Cover-Time Planning, Available-to-promise, Make-to-order.

\section{INTRODUCTION}

For a manufacturing company to satisfy the customer with a delivery time shorter than the total leadtime through the whole bill of materials, a part of the manufacturing process must have started before the customer order arrives. To achieve this Material Requirement Planning (MRP) or Reorder point systems (ROP) is mostly used in practical computer based applications. MRP implies that for each end item a master production schedule (MPS) is created, specifying delivery times and order quantities from a forecasted demand. The master production schedule is exploded to downstream items through bills of materials (the product structures). Demand is netted towards available inventory, thereby determining if a new planned order should be created or an old open order should be rescheduled with a new delivery date (cf. Orlicky [1]). Ordinary ROP systems imply that for each item a reorder point or reorder level is defined. When the inventory position of the item is less than this level, a new replenishment starts for the item through a purchase or manufacturing process. The reorder level is set so that the available inventory will satisfy demand until replenishment arrives. Descriptions of MRP and ROP systems can be found in a huge number of articles and textbooks, e.g. Vollman et al [2], Krajewski and Ritzman [3], Hopp and Spearman [4], Vonderembse and White [5] and many others.

MRP or possible alternatives are extremely important when these techniques and the company's ability to use them decide how clever the company is at adapting to the customer's requirements. A critical decision for a company selling manufactured products is the determination of delivery times and quantities of incoming customer orders. Promising deliveries of larger amounts, and earlier, then the company later can perform, will annoy and make problems for the customer. Promising deliveries with a too long delivery time will also make problems for the customer. The customers will probably prefer another supplier in the future. The performance of these techniques will decide the level of customer service, how much capital will be invested in work-in-process and inventories, what efficiency and costs will be created in the production facility, and in the end what financial result the company achieves. Johnson and Bröms [6] point out that what decides an organisation's long-term profitability is the way it organises its work, not how well its members achieve financial targets. 
In Sweden, a variant of ROP is getting attention and applications. In this variant, an explicit re-order point is not calculated, but instead a coverage analysis is made by estimating how long the already decided upon replenishment will cover the expected demand, i.e. called cover-time. If the cover-time is longer than the lead-time plus a possible safety time for an item there is no need to order any new replenishments at that moment. For example, Swedish software companies Monitor (http://www.monitor.se) (with their product Monitor) and IBS (http://www.ibssverige.se/) (with their product ASW) sell and help customers to install computer systems with this type of analysis instead of or as a complement to ordinary reorder point systems (or MRP). Subtracting the lead-time from the cover-time creates a priority number, and then the different manufacturing orders for the different items can be sorted and handled in priority-sequence to avoid shortages. This variant of a reorder point system is called Cover-Time Planning (CTP). The idea of CTP have previous been presented in Segerstedt [7], [8], in a Swedish textbook and some Swedish articles. Swedish companies declared they were using CTP in 2000, and also satisfied with the technique, cf. Jonsson [9], Jonsson and Mattsson [10]. However, most companies probably did not use CTP completely in the way defined and described below.

\section{A SMALL NUMERICAL EXAMPLE}

To present CTP further and illustrate the differences between MRP and CTP a small numerical example is introduced. The example consists of only two $A$ and $B$. Figure 1 shows the assumed bill of materials (product structure) in action.

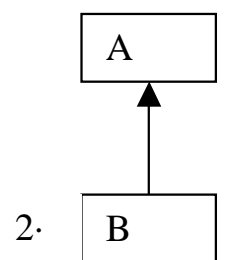

Figure 1: The bill of materials for the example

$A$ is an end-item and $B$ is its component. The manufacturing of one piece of $A$ needs two pieces of $C$.

Table 1: Item data

$\begin{array}{cccc}\text { Item } & \begin{array}{c}\text { Lead-time } \\ \text { (working } \\ \text { days) }\end{array} & \begin{array}{c}\text { Fixed order } \\ \text { quantity }\end{array} & \begin{array}{c}\text { Initial } \\ \text { inventory }\end{array} \\ A & 3 & 25 & 2 \\ B & 15 & 50 & 33\end{array}$

The cumulative lead-time for $A$ is $3+15=18$ working days; meaning that if today an increase of the orders for $B$ start, it will take 18 working days until the outflow of $A$ increases. Until these 18 days have passed the outflow of $A$ is dependent on what purchase orders that have been placed for $B$ in the previous 18 days. In a "real" application the cumulative lead-time is, of course, not always exactly 18 working days, it is a "stochastic" variable dependent of the actual work load, stochastic processing times, etc. However, it is far from zero, it takes time, and the best estimate we have is 18 working days until an increased purchase of $B$ results in an increased output of $A$.

If the production capacity of $A$ and $B$ are restrained to current outflows and are not expanded an increasing outflow of $A$ will not happen even if we increase the inflow of $B$. This important fact must be remembered throughout this article. If in the following text an increase of the outflow is scheduled a necessary increase in the production capacity is also assumed to be accomplished.

A planning horizon of 23 time periods (working days) is used. The longest cumulative lead-time is 18 time periods. The planning horizon must exceed the longest cumulative lead-time, otherwise the 
forecast (master production schedule) will not; when it is exploded down to the lowest level in the product structure create a proper and correct demand for these items. A too short planning horizon, even if it is longer than the longest cumulative lead-time, will lead to that during one MRP-calculation there will be no signals for replenishment but in a future MRP-calculation signals will be created but with a required finish time in bygone time, and the replenishment will probably be delayed and create shortages and discontented customers.

Expected demand for the end-item $A$ is estimated with the following demand rates in Table 2 (units/ working day) for the coming 23 time periods.

Table 2. Expected demand for $A$

\begin{tabular}{lcc|c|c|c|c|c|c|c|} 
Period (day) & 1 & $\ldots$ & 6 & 7 & $\ldots$ & 15 & 16 & $\ldots$ \\
Item $A$ & $\mathbf{5}$ & $\mathbf{5}$ & $\mathbf{5}$ & $\mathbf{4}$ & $\mathbf{4}$ & $\mathbf{4}$ & $\mathbf{5}$ & $\mathbf{5}$
\end{tabular}

\subsection{Material Requirements Planning (MRP)}

First MRP is used for the example. For items $A$ there are some current customer orders, they are known future demand, but also realised forecasts. The original forecasts must be reduced with incoming customer orders; then the right level for the expected "outflow" is created. The customer orders can then also be part of the MRP-calculation, so that deliveries will not be forgotten. The original forecast and realised customer orders cannot be used together in the MRP-calculation, then to lower levels in the bill of materials is exploded a level of "outflow" higher than is really expected, creating excessive inventories.

Table 3 shows the master production schedule (MPS) for Item A in the row Gross requirement. The row Scheduled issues shows the customer orders. The APICS (American Production and Inventory Control Society) nomenclature (from St. John [11]) is followed. In period 1, 25 pieces were originally forecasted, which was subsequently consumed by customer orders in periods $1,2,3$, and 5 . For period 6, 21 pieces were originally forecasted (4 units/working day in 4 days and 5 units/working day for 1 day equals 21 for the week). A customer order in period 7 consumes 5 of these units and leaves 16 pieces for future customer orders. The forecast for period 11 was originally 20 pieces, but 3 units are consumed by a customer order in period 11 . The row Scheduled receipts shows open orders, orders that have already started for replenishment. Projected on hand (inventory) presents future inventory if no new replenishments occur. Projected available shows future inventory when scheduled receipts have been rescheduled to delivery dates when they really are required and when necessary planned receipts are added. The row Planned receipts presents when in time a new replenishment is necessary, and with what quantity (here a fixed order quantity), so as to avoid a negative projected available or a future negative inventory level. A negative projected on hand is initially avoided by a rescheduling of already open orders (scheduled receipts), thereby presenting new due dates that coincide with now existing time points of requirements. If a scheduled receipt now has a due date that is too early, then the due date is postponed to a point in time when the replenishment is really required, meaning that the original lead-time can be disregarded, be expedited, or deferred quite considerably by this rescheduling. But it would be more unrealistic to let a new planned order cover the possible negative inventory, as it would force the new planned order to have a much shorter lead-time than an already started order that may have been in manufacturing for a while. This rescheduling "mechanism” is the base of MRP's time phasing technique, a technique to schedule replenishments just before the withdrawals take place, but also a technique that creates MRP-nervousness. Planned release presents when the planned receipt or planned order has to start according to the expected lead-time and when the component is in demand. When a planned receipt is registered and started (opened) it becomes a scheduled receipt. The scheduled receipt with delivery time in past time for item $A$ is not needed until period 1 , so it is rescheduled to that date. As the present time is at the beginning of period 1 , a new release for replenishment of $A$ can wait for another two periods. 
Table 3: MRP Item A

\begin{tabular}{|c|c|c|c|c|c|c|c|c|c|c|c|c|c|c|c|c|c|c|c|c|c|c|c|c|}
\hline Week, day & - & 1 & 2 & 3 & 4 & 5 & 6 & 7 & 8 & 9 & 10 & 11 & 12 & 13 & 14 & 15 & 16 & 17 & 18 & 19 & 20 & 21 & 22 & 23 \\
\hline Gross req. & & 0 & & & & & 16 & & & & & 17 & & & & & 25 & & & & & 25 & & \\
\hline Sch. issues & & 5 & 8 & 7 & & 5 & & 5 & & & & 3 & & & & & & & & & & & & \\
\hline Sch. receipts & 23 & (23) & & & & & & & & & & & & & & & & & & & & & & \\
\hline Proj. on hand & 2 & 20 & 12 & 5 & 5 & 0 & -16 & -21 & -21 & -21 & -21 & -41 & -41 & -41 & -41 & -41 & -66 & -66 & -66 & -66 & -66 & -91 & -91 & -91 \\
\hline Proj. available & & 20 & 12 & 5 & 5 & 0 & 9 & 4 & 4 & 4 & 4 & 9 & 9 & 9 & 9 & 9 & 9 & 9 & 9 & 9 & 9 & 9 & 9 & 9 \\
\hline Plan. receipts & & & & & & & 25 & & & & & 25 & & & & & 25 & & & & & 25 & & \\
\hline Plan. release & & & & 25 & & & & & 25 & & & & & 25 & & & & & 25 & & & & 25 & \\
\hline
\end{tabular}

The scheduled receipt in period 11 for item $B$ will already be needed in period 8 to cover the planned release of 25 units of $A$ (cf. Table 4). However, this is not enough; a new replenishing order should have been started some two periods ago to assure production of another 25 units of $A$. This indicates that the forecast of $A$ is too "heavy", i.e. it will be difficult to satisfy the demand. Instead, in the master production schedule of $A$, some delivery quantities should be postponed for the future. However, in practice with thousands of items, there is no time for a change, and one often has to assume that the lead-time can be shortened, as in this case.

Table 4: MRP Item B

\begin{tabular}{|c|c|c|c|c|c|c|c|c|c|c|c|c|c|c|c|c|c|c|c|c|c|c|c|c|}
\hline & - & 1 & 2 & 3 & 4 & 5 & 6 & 7 & 8 & 9 & 10 & 11 & 12 & 13 & 14 & 15 & 16 & 17 & 18 & 19 & 20 & 21 & 22 & 23 \\
\hline Gross req. & & & & 50 & & & & & 50 & & & & & 50 & & & & & 50 & & & & & \\
\hline Sch. issues & & & & & & & & & & & & & & & & & & & & & & & & \\
\hline Sch. receipts & & & 49 & (49) & & & & & (50) & & & 50 & & & & & & & & & & & & \\
\hline Proj. on hand & 33 & 33 & 82 & 32 & 32 & 32 & 32 & 32 & -18 & -18 & -18 & 32 & 32 & -18 & -18 & -18 & -18 & -18 & -68 & -68 & -68 & -68 & -68 & -68 \\
\hline Proj. available & & 33 & 32 & 32 & 32 & 32 & 32 & 32 & 32 & 32 & 32 & 32 & 32 & 32 & 32 & 32 & 32 & 32 & 32 & 32 & 32 & 32 & 32 & 32 \\
\hline Plan. receipts & & & & & & & & & & & & & & 50 & & & & & 50 & & & & & \\
\hline Plan. release & 50 & & & 50 & & & & & & & & & & & & & & & & & & & & \\
\hline
\end{tabular}

\subsection{Cover-Time Planning (CTP)}

Cover-Time Planning (CTP) implies that expected demand rates for end items, or items on suitable highest level in the bill of material, are "derived down" (exploded) to underlying levels using the information in the bill of materials and reported lead times, to calculate and estimate demand rates over a time horizon for all items. Thereafter each item is treated separately from all other items. For every item a current "supply" is defined:

Supply = On hand inventory - Backorders

+ Planned replenishments

The time this already activated or started "supply" will last to cover expected future demand is called "cover-time". (A similar notion is "run-out time", but it is often used for telling how long on hand inventory will last; how long the "supply" will last is based on a coverage analysis therefore cover-time is used.) If the demand rate is stable and the lead time short, the cover-time can be calculated as:

\section{Cover-Time $=$ Supply $/$ Demand rate}

If the lead time is long and the demand rate varies a more accurate calculation of the cover-time has to be undertaken. Figure 2 illustrates an example where a more accurate calculation is needed. The figure intuitively shows how the cover-time is calculated. - 


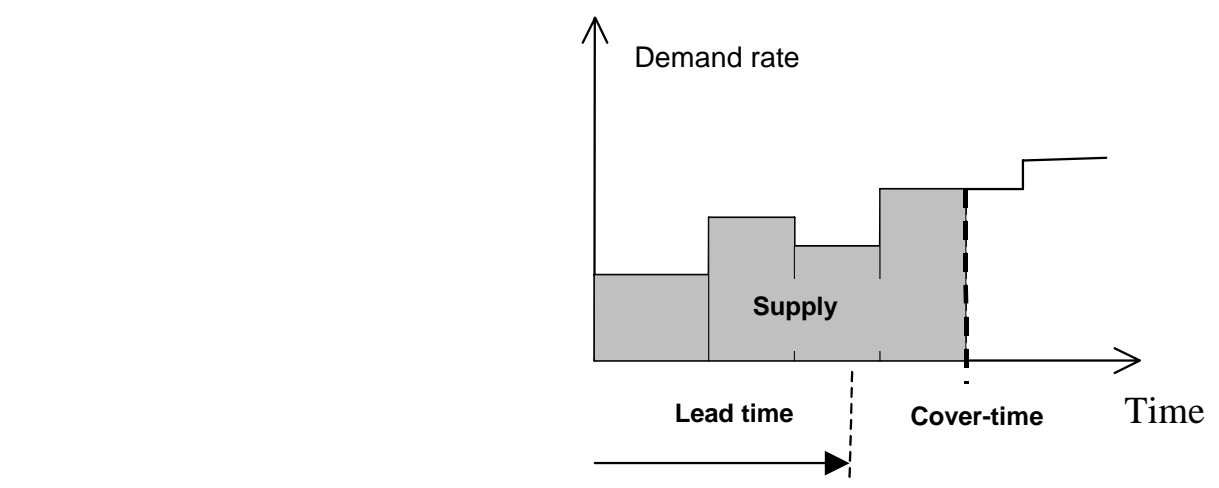

Figure 2: An example with varying lead time

When for an item if:

Cover-time < lead time (incl. inspection interval) + possible buffer time

Available on hand inventory within lead time $<0$

Then CTP creates a signal that a further replenishment is needed.

The supply for item $A$ is $2+23=25$ (cf. Table 5). This supply is expected to cover the demand in 5 periods; cover-time is 5 periods (days), because the expected demand rate is 5 units/period. Inspection and decision of if replenishment is necessary is not done continuously but every day (period), i.e. inspection time is one period. For simplicity it is assumed that no buffer or safety time is required in the example. For item $A$ lead-time + inspection time is 4 periods; which is less than the cover-time, so a new replenishment is not presently necessary. Projected on hand in period 4 is positive, but if it had been negative (according to equation (4)) it would have explained an instant replenishment. To prevent this we would have been forced to start replenishment right away and not wait until the next day. Observe that in Table 5 and 6, supply is "deferred" by the lead-time from a pedagogical point of view. It is now the beginning of period 1 , and it is not really possible to influence projected on hand inventory before period 4 for item $A$ (period 16 for item $B$ ) due to the existing lead-time. Planned receipts for CTP (in Table 5 and 6) are calculated such as supply plus planned receipts satisfy expected demand.

Table 5. CTP Item $\boldsymbol{A}$

\begin{tabular}{|c|c|c|c|c|c|c|c|c|c|c|c|c|c|c|c|c|c|c|c|c|c|c|c|c|}
\hline Week, day & - & 1 & 2 & 3 & 4 & 5 & 6 & 7 & 8 & 9 & 10 & 11 & 12 & 13 & 14 & 15 & 16 & 17 & 18 & 19 & 20 & 21 & 22 & 23 \\
\hline Demand rate & & 5 & 5 & 5 & 5 & 5 & 5 & 4 & 4 & 4 & 4 & 4 & 4 & 4 & 4 & 4 & 5 & 5 & 5 & 5 & 5 & 5 & 5 & 5 \\
\hline Sch. issues & & 5 & 8 & 7 & & 5 & & 5 & & & & 3 & & & & & & & & & & & & \\
\hline Sch. receipts & 23 & & & & & & & & & & & & & & & & & & & & & & & \\
\hline Proj. on hand & 2 & 20 & 12 & 5 & 5 & 0 & 0 & -5 & -5 & -5 & -5 & -8 & -8 & $\ldots$ & & & & & & & & & & \\
\hline "Supply" & & & & & 25 & & & & & & & & & & & & & & & & & & & \\
\hline Plan. receipts & & & & & & & 25 & & & & & & 25 & & & & & 25 & & & & & 25 & \\
\hline Plan. release & & & & 25 & & & & & & 25 & & & & & 25 & & & & & 25 & & & & \\
\hline
\end{tabular}

It is important to notice that the calculation of planned receipts is only necessary when an estimate of current capacity loads in different machines is desired, when Capacity Requirements Planning is performed. These planned receipts, together with their routings, estimated operation and setup times in different machines or other production facilities, create information to forecast how much and when capacity is required according to current estimated demand. The planned receipts are not time-phased with down-stream items like in the MRP-calculation; but the important thing is that the required volume per time unit is correct. However, this makes CTP predominantly based on sharp open orders; 
planned receipts are not really planned orders of the same kind as for MRP. Planned orders are a required part in an MRP-calculation, but planned receipts in the CTP-calculation are only required for capacity load estimations, making the CTP-calculation much less extensive than the MRP-calculation.

Two units of item $B$ are required to produce one unit of item $A$, so the demand rate of $B$ is twice as large as that of $A$ (cf. Table 6). Due to the lead time of $A$ an increase (or decrease) happens three periods earlier for $B$ than the originating change of $A$. Cover-time is $3+9+(132-3 \cdot 10-9 \cdot 8) / 10=15.0$ days; therefore it is necessary to order now because the lead-time plus inspection time is 16 days.

Table 6. CTP Item B

\begin{tabular}{|c|c|c|c|c|c|c|c|c|c|c|c|c|c|c|c|c|c|c|c|c|c|c|c|c|}
\hline Week, day & - & 1 & 2 & 3 & 4 & 5 & 6 & 7 & 8 & 9 & 10 & 11 & 12 & 13 & 14 & 15 & 16 & 17 & 18 & 19 & 20 & 21 & 22 & 23 \\
\hline Demand rate & & 10 & 10 & 10 & 8 & 8 & 8 & 8 & 8 & 8 & 8 & 8 & 8 & 10 & 10 & 10 & 10 & 10 & 10 & 10 & 10 & 10 & 10 & 10 \\
\hline \multicolumn{25}{|l|}{ Sch. issues } \\
\hline Sch. receipts & & & 49 & & & & & & & & & 50 & & & & & & & & & & & & \\
\hline Proj. on hand & 33 & 33 & 82 & 82 & 82 & 82 & 82 & 82 & 82 & 82 & 82 & 132 & 132 & 132 & $\ldots$ & & & & & & & & & \\
\hline \multicolumn{24}{|l|}{ "Supply" } & \\
\hline Plan. receipts & & & & & & & & & & & & & & & & & 50 & & & & 50 & & & \\
\hline Plan. release & & 50 & & & & 50 & & & & & & & & & & & & & & & & & & \\
\hline
\end{tabular}

CTP has similarities to the CONWIP concept (cf. Spearman et al [12]). The work-in-process (WIP) is restricted, if there is no withdrawal of the end-item, then there are no withdrawals of subassemblies and in turn no withdrawals of their components,. However, contrary to Kanban, but like CONWIP CTP does not control WIP at every work centre. Spearman and Zazanis [13] argue that the effectiveness of pull systems does not result from pure pulling as in Kanban but from limiting WIP and WIP variability. They mean that controlling WIP levels at every work centre in the production process may be more restrictive than necessary. Setting WIP levels for all work centres also complicate the problem of managing, if demand changes and/or bottlenecks moves, the number of cards (when using Kanban) must be adjusted accordingly.

\section{MASTER PRODUCTION SCHEDULING WITH AVAILABLE-TO-PROMISE}

Manually introducing a customer order in the master production schedule (MPS), as was done above, can be a bit "clumsy", especially if there are hundreds of end-items that should be serviced. Therefore, many companies use a Master Production Scheduling system (MPS-system) that creates a slightly different MPS than was used for the above MRP-calculation. This system is mostly available in the company's own computer system for materials and production control, or the system for Enterprise Resource Planning (ERP), e. g. SAP/R3, Baan Triton, Movex and other ERP-systems.

Vollman et al [2], Krajewski and Ritzman [3], Vonderembse and White [5] all present introductory discussions of MPS-systems. Here is argued how the MPS-system should be constructed and how it should be used, in detail. The influence comes from studies of practical applications (cf. Segerstedt [14]) and from own practical experience as a production control and production manager.

Table 7 shows a suggested MPS-system, which is basically only a spreadsheet model, but in practice it should be incorporated in the ordinary ERP-system used by the company. Item $A$ from previous section is also used here, with a fixed order quantity $(=25)$ for deciding new MPS-quantities. In Table 7 a "week-scale" is used, the time periods in e.g. Table 3 and 5 are here added together in aggregate time periods (weeks). Forecasted demand (in Table 7) is the original forecast. Other requirements, though not used in our example, can be interplant orders for service parts and orders for filling up inventories. Customer orders booked shows the amount already promised for delivery. Scheduled receipt (MPS) is a type of a "firm planned" MPS - it is a Planned receipt (MPS) from previous periods and MRPcalculations that are now released and exist as a scheduled receipt. It is now a manufacturing order, with a specific content, because of that it is treated as firm. 
Table 7. Available-to-promise Item A, MPS-quantity $=25$

Week

late $\begin{array}{lllllll}1 & 2 & 3 & 4 & 5 & 6\end{array}$

Forecasted demand

Other requirements

Customer order booked

Scheduled receipts (MPS)

Planned receipts (MPS)

Proj. on hand

Available-To-Promise

Cumulative A-T-P

\begin{tabular}{|c|c|c|c|c|c|c|}
\hline & 25 & 21 & 20 & 20 & 20 & 20 \\
\hline \multirow{3}{*}{23} & 25 & 5 & 3 & & & \\
\hline & & & & & & \\
\hline & & 25 & 25 & 25 & 25 & 25 \\
\hline \multirow[t]{3}{*}{\begin{tabular}{|l|}
2 \\
\end{tabular}} & 0 & 4 & 9 & 14 & 19 & 24 \\
\hline & 0 & 20 & 22 & 25 & 25 & 25 \\
\hline & 0 & 20 & 42 & 67 & 92 & 117 \\
\hline
\end{tabular}

The inventory on-hand at the beginning of period 1 is 2 . The customer orders are the same orders as in Tables 3 and 5. The following connection is used in Table 7:

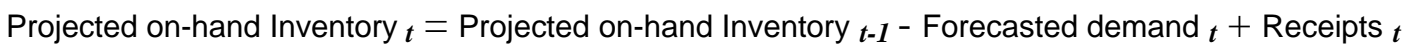

Current inventory on hand is decreased by possible late Customer orders booked or Other requirements, but otherwise Customer orders booked does not influence projected on-hand.

Table 7 is used in two stages and with two aims:

1) In the table MPS-quantities are calculated, quantities which are used in the next MRP-calculation as its MPS. Before that the forecasted demand may be changed due to new information. However, since the cumulative lead-time is 18 working days, no change in demand, except maybe a decrease, is executed in the nearest 4 weeks. Something else is useless, and would mostly create troubles late deliveries etc, because it takes approximately 18 time periods before the outflow can be increased. From the previous MRP-calculation we have already registered and started planned receipts, now as open orders or Scheduled receipts (MPS). The MPS-system automatically calculates Planned receipts (MPS) according to connection (7) and thereby avoid projected on hand becoming negative. Here, a fixed MPS-quantity of 25 units is used (also possible to use is a fixed period MPS-quantity). The MPSquantities are then used in the next MRP-calculation.

2) After the completion of MPS-quantities from a possible forecast change, in week 5 and ahead, the table is used for promising delivery dates for new customer orders.

Available-To-Promise for deliveries of $A$ in week 1 is $0(=2+23-25)$, available to promise in week 2 is $20(=25-5)$, available to promise in week 3 is $22(=25-3)$, available to promise (A-T-P) in weeks 6 and 7 is $25(=25-0)$, etc. If we book less than 20 units of customer orders in week 2, booking more than 22 units in week 3 might be possible. If we book a customer order, e.g. in week 3, the MPS-system automatically decreases A-T-P from the previous 22 units by the amount of the customer order, Cumulative A-T-P decreases by the same amount. A-T-P may be negative, but Cumulative A-T-P must never be negative or less than zero; if so, a delivery is promised whose requirement of components has not previously been forecasted, manufactured, or purchased. If Cumulative A-T-P is zero during a certain time period, a new customer order must be given a delivery date beyond this time period.

When the MPS-quantities from the MPS-system in Table 7 are used as “inputs" in the MRPcalculation, then slightly different results as compared to Tables 3 and 4 will occur.

To establish an available-to-promise system for Cover-Time Planning is easy. It is only necessary to control that the cumulated volume of promised customer orders is less or equal to the cumulated forecasted demand, which is only a simple addition to the previous used CTP-tables, cf. Table 8. 
Table 8. A-T-P: CTP Item A

\begin{tabular}{|c|c|c|c|c|c|c|c|}
\hline Week & late & 1 & 2 & 3 & 4 & 5 & 6 \\
\hline Forecasted demand & & 25 & 21 & 20 & 20 & 20 & 20 \\
\hline Other requirements & & & & & & & \\
\hline Customer order booked & & 25 & 5 & 3 & & & \\
\hline Available-To-Promise & & 0 & 16 & 17 & 20 & 20 & 20 \\
\hline Cumulative A-T-P & & 0 & 16 & 33 & 53 & 73 & 93 \\
\hline
\end{tabular}

As with MRP, customer orders should be accepted with delivery times such that Cumulative A-T-P is never negative. Naturally, it is possible to deliver a customer order on time even if Cumulative A-T-P is negative, but then the actual lead-time must be decreased or there must exist excess inventory. However, it is dangerous to rely on the lead-time being shortened and the availability of excess inventory, it is then better to plan according to Cumulative A-T-P.

Suppose that time pass and things develops (under 5 time periods/days) for item $A$ in Table 7; and now it is in the beginning of week 2. During week 1 the scheduled receipts of 23 units have arrived. New customer orders have been received: 16 units for delivery in week 2, 10 units for delivery in week 3, 30 units for delivery in week 4 and 10 units for delivery in week 5 . The customer order of 5 units in week 1 day 5 is still not delivered, but the other customer orders for delivery in week 1 have been expedited; therefore, therefore there are 5 units of inventory at the beginning of week 2. Table 9 shows how Table 7 has changed by the new customer orders and after customer orders have been dispatched. It is not possible to promise 12 units for delivery in week 3, even if A-T-P shows 12 there, then cumulative AT-P in week 4 would become negative. Until week 4 and earlier the maximum units possible to promise is 11 units.

Table 9. Available-to-promise Item A, MPS-quantity $=25$

Week

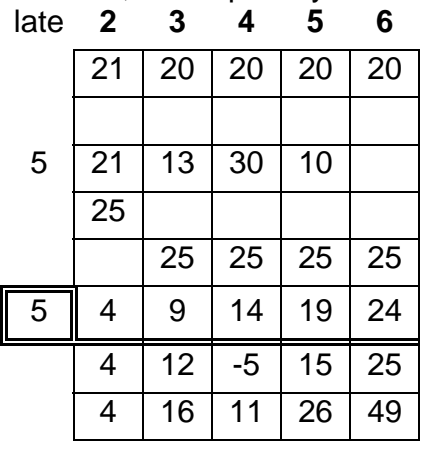

Forecasted demand

Other requirements

Customer order booked

Scheduled receipts (MPS)

Planned receipts (MPS)

Proj. on hand

Available-To-Promise

Cumulative A-T-P

\section{PLANNING BILLS}

In real practical application we may have a huge number of end-items that need delivering to customers. The end-items may be special variants of a product, where forecasting every individual enditem may be rather laborious and generate a lot of work, and still the forecast reliability is poor. Therefore, it may be useful to just forecast the total number of the product, an aggregate item that does not have a real product configuration (bill of materials, product structure) and from previous experience automatically estimate that if $21 \%$ of previous sales of the product have consisted of end-item $E$ (with a real bill of materials, product structure), so will it also be in the future.

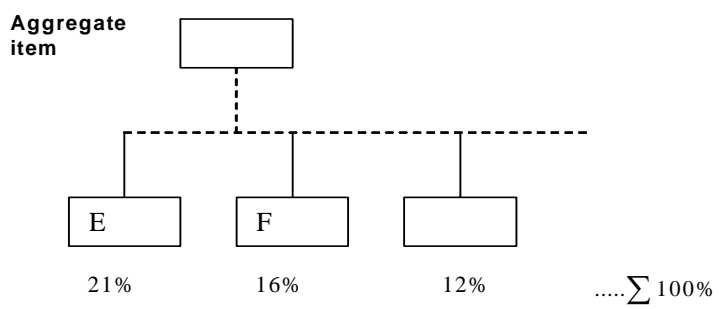

Figure 3: A fictive item for planning 
The forecast for the aggregate (fictive) item is then automatically divided in the MRP explosion between its "components", as shown in Figure 3. It is also possible to let this fictive product structure have several structural levels. Segerstedt [14] presents an example of a company producing electrical motors using a two level planning bill of material, i.e. two structural levels before coming to the real end-item with an ordinary product structure.

When we have previously forecasted a quantity comprising of $16 \%$ of the original forecast for the aggregate item, is it now possible to promise delivery of 12 units of item $F$ in special week and special day? This is a difficult problem to handle without any administrative help. Using a planning bill of material necessitates using a system showing "available-to-promise", a system that can help the user keep track of the previous forecasts. Observe that the forecast in Table 7 for item $A$ can be automatically determined from a forecast of an aggregate item. Also note that the "planning bill" has a preserving effect, it is difficult to adopt a change in the mixture, i.e. if the customers in the future want less of $E$ and more of other items. A percent change must be activated in the future, with a time delay (postponing) equal to the cumulative lead-time. Both MRP and CTP can use planning bills; the only difference being that for CTP the forecast is presented with a demand rate.

\section{FORECASTING OF MODULES}

The schematic "product structure" in Figure 4 is a base for the coming discussion. Suppose the demand for end-items $A$ and $B$, and item $C$ is very irregular, rather small, and therefore difficult to forecast. Any start of production for these items before the customer order arrives is not done, because the risk for obsolete and not wanted inventories is too high. However, due to the gathered demand of item $D$ from items $A, B$, and several other possible items, the demand of item $D$ is rather regular, is a larger amount, and easy to forecast. To achieve a short delivery time, it may also be necessary to forecast $D$. The production/purchase of item $D$ must already have begun before the customer order arrives to secure a delivery time competitive in the market.

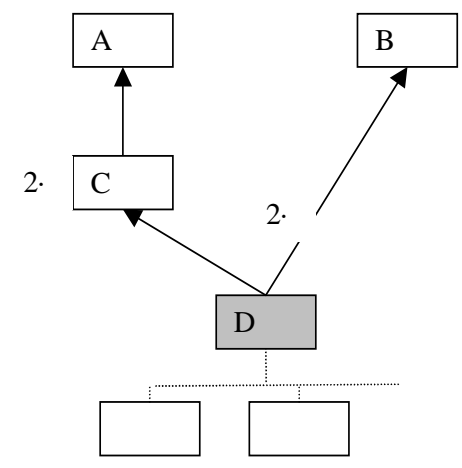

Figure 4: Gathered demand of item $D$

Observe that in a practical situation, item $D$ in turn may consist of components in several structural levels. Item $D$ is a module in different end-items, end-item which are often variants of a special product (e.g. truck loaders, high power circuit breakers, etc.).

Considering previous forecasts of $D$ and already promised customer orders of different end-items using $D$, what deliveries of an end-item using module $D$ can be promised? In practical situations, using MRP, this is a very difficult problem to solve. If we use a material production schedule for the module we cannot include the real customer orders for the end-items $A, B$, etc. in the MRP-calculation. If both original forecast and the realised customer orders together are used in the MRP-calculation, then to lower levels in the bill of materials requirements higher than really expected is exploded. But reducing the MPS with the different customer orders is now much trickier than in the numerical example (Table 3). To reduce the MPS with incoming customer orders, or keep track of promised deliveries of new customer orders and ensure they are in line with previous forecasts, a type of A-T-P and MPS-system is needed. 
In this case a "reverse planning bill" is needed, a fictive aggregate item " $D$ " containing the amount of module $D$ one estimates to sell and a planning bill specifying the estimated partitions of " $D$ " that one believes will be $A, B$, etc. However, this forces forecasts of the irregular and rather small demand of $A$, $B$, etc., which from the beginning was something that was wished to keep away from! It probably also hinders the production of what the customer really wants due to the planning bills preserving effect (mentioned above).

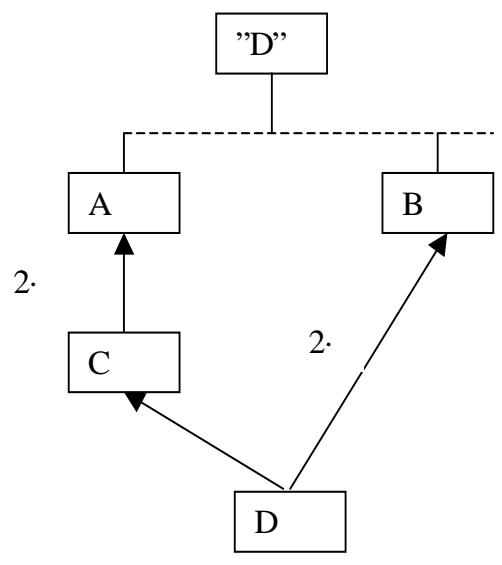

Figure 5: Planning bill for the module

The number of planning bills increases with the numbers of modules. Many planning bills create a lot of complex manual administration work to maintain validity in the planning process.

Another way to try and solve the problem "using MRP and only forecast modules" is to separate the different items into completely separate inventories. The MPS of $D$ is then treated as the true external demand for those items, in structural levels lower than $D$, laying in the "Inventory of $D$ (modules)". In the "Inventory of $A, B$ (non-modules)" the MPS of the modules are then treated as incoming deliveries (purchase orders, scheduled receipts). If the scheduled receipts of $D$ are not required, due to existing customer orders of $A, B$ etc., the MRP-calculation will then postpone them to the future. Keeping track of what quantities of $A, B$, etc are possible to promise to customers in different time periods will be difficult due to the availability of $D$ and other modules (which depends on previous forecasts in action).

A third way to forecast only modules and manufacture end-items when the customer order arrives is just to abandon MRP. Then only $D$ and items in underlying product structures to $D$ are produced with help of reorder points. New customer deliveries are then promised as long as the inventory position of $D$ is positive. This is probably an easier and more suitable solution than a troublesome MRP application!

If a reorder point system is a possible solution, Cover-Time Planning is supposed to be an even better solution. The idea behind CTP is to just create assistance to manufacture modules according to forecasts and make end-items to orders. When using CTP no expected demand rates for items $A, B$, and $C$, are used; only for item $D$. Production of item $D$ starts according to the expected demand rate (as stated by equation (3)) and production of $A, B$, and $C$ starts when needed (as stated by equation (4)). To promise large deliveries of $A$ and $B$ whose requirements of $D$ not have been previously forecasted must be avoided. If not so, this will create future shortages of $D$ and late deliveries of $A$ and $B$. Therefore "projected on hand" for the modules ( $D$ etc.) must never become negative within the lead-time of the module in question, because a new replenishment order placed today will not be available until the lead-time has passed. In a computer system this can be solved by a "beep" signal every time one tries to register a customer order, thereby creating this for a module. This becomes a type of a "material clearance" system down through the product structure to the forecasted items/modules. In such a system an item like $C$ then only prolongs the lead time from $A$ to $D$, and may, like $C$, change the amount of demand due to how many items of $C$ are being used by $A$. 
Observe that it is not possible to build a similar system with MRP; its MPS must be changed by incoming customer orders through a manual operation (like in Tables 3) or by an MPS-system (like in Table 7). This is because the MPS intervenes in the calculation in a completely different way than the "MPS" of CTP. MRP is really a "make to stock"-system; if the customer orders coincide with the MPS everything is OK. But if the customer orders differ from the MPS, something must be changed in the MPS or the customer orders to get the right things to the market. The MPS of MRP is the external demand that is exploded to the underlying structural level using actual lot size techniques. The MPS of CTP is only a forecasted demand rate exploded to underlying structural levels, presenting forecasted demand rates for the components, but not intervening in scheduled issues and scheduled receipts (as MRP does).

\section{ENTERPRISE RESOURCE PLANNING}

Vollman et al [2] write that MRPII enables managers to test "what if" scenarios, and allows management to project the dollar value of shipment, product costs, overhead allocations, inventories, backlogs, and profits. However, nowadays MRPII seems to have disappeared from sales booklets of software companies selling computer systems for material and production control; MRPII is replaced with Enterprise Resource Planning (ERP). Vollman et al. [2] do not mention ERP, probably because the term was used very rarely when the book was being prepared for printing. However, one of the coauthors has recently written "Why ERP?" a novel about an SAP computer system implementation (Jakobs and Whybark [15]). Krajewski and Ritzman [3] had time to incorporate the term ERP in their textbook. MRPII has evolved to a new form, ERP. It is a system that has additional capabilities for quality management, field service, maintenance management, distribution, marketing, and supplier management. Krajewski and Ritzman mean that with ERP the focus is on the external supply chain. ERP also enables the firm to deal directly with suppliers to assess the availability of their resources.

What Krajewski and Ritzman refer to is not a new MRP-calculation, rather that the "internet" technique has developed and can be used in communication with suppliers (and customers). MRPII and ERP are still based on the MRP-calculation from Orlicky [1], and the "forward visibility" and the "what if" scenarios are based on the planned orders generated from the MRP-calculation. These "scenarios" are based on planned orders that will not coincide with real future (open) orders. Even in a small numerical example like in this article, if one let time pass and assume everything happen according to plan creates many rescheduling of open orders. The author has practical experience as an MRP user for almost 7 years; the list of suggested reschedulings was always too large to really accomplish something out of it, though any change of the MPS beyond the maximum cumulative leadtime was omitted. It was only possible to react on a few of the recommendations, and then mostly from suggestions for an earlier start to avoid future material shortages, in that way the inventory levels increased. This is also in line with a study of Euwe et al [16].

All information created from the planned orders of MRP can also be created from the planned orders of CTP, e.g. workload in different machines, forecasts to suppliers, etc. Other positive things mentioned as characteristics of ERP such as quality management, marketing, etc., are just additions not dependent on the MRP-calculation and can also be additions in a system based on CTP. This means that it is also possible to build an ERP system around CTP, but not around a pure reorder point system because it cannot create a "forward visibility" due to its lack of future planned orders.

\section{SUMMARY, CONCLUSIONS AND EXTENSIONS}

An MPS-system (Master Production Scheduling system) is useful for both MRP and CTP, especially for not promising customers delivery quantities that have never been forecasted. The cumulative leadtime decides how far the forecasts must be frozen, and the MPS-system helps the user to keep them frozen.

A too short planning horizon creates problems for MRP. MRP does not succeed in creating the necessary replenishment information on time. The planning horizon used by MRP must therefore be longer than the longest cumulative lead-time found by the different end-items with large surpluses. 
Larger the order quantities used, the greater the surplus used. CTP needs only a planning horizon that coincides with the cumulative lead-time. (Note that the user of CTP may present to the system only one forecasted demand rate for the forecasted items; this demand rate is then supposed to be in order during the entire planning horizon. If another demand rate should be in order, the user just tells from which date this new demand rate will be used. In practice, it is unpractical to work with a table like in our examples; instead it would be based on "linked lists" or another computer programming technique.)

The main idea behind CTP is to facilitate customer order production. If MRP handles "assemble-to order" or "make-to order", tricks like planning bills, separate inventories etc. must be introduced. It is still difficult to know if the material and components in the customer order have really been forecasted and will be available on time.

Orlicky [1] does not support safety stocks for MRP, which is understandable because it means that the MRP-calculation then protects "projected available" to be not less than the safety stock, and not as before to not less than zero. This may create a surplus inventory since it is also difficult to calculate and estimate what a proper safety stock should be for MRP. Another "safety arrangement" for MRP is safety lead times, using lead times longer than expected. However, this may be a "self fulfilling forecast"; the work-in-process increases due to earlier starts because lead time is prolonged with safety times; the increase in WIP prolongs the throughput time (lead time) (cf. Hopp and Spearman [4]). The natural similarity to ROP's safety stocks is for CTP safety or buffer times, so this may also be an obstacle for CTP. Further studies are necessary, both in practical applications and/or with simulation. However, there is no doubt that if everything happened according to the schedule with no changes in external demand and always the same expected lead times, then MRP would be the ultimate method. But MRP is a deterministic model over a stochastic reality, and simulation studies have shown that MRP has difficulties to handle variations in demand and lead times (Segerstedt [7], [17]). Therefore, a simpler robust technique like CTP is possible to use without inferior results concerning delivery service and capital investments in inventory and work-in-process. CTP might prove to be a successful technique in ERP-systems, due to its simplicity, speed in computer calculations, stability against variations, and ability to handle customer-order production. Regardless of what technique is used, MRP or CTP, disorder and careless delivery promises will result in low performance. Therefore, assistance from a well-thought out and helpful MPS-system is necessary. Finally, Table 17 presents important characteristics of the three discussed techniques for multi-level production: 


\begin{tabular}{|c|c|c|c|}
\hline Characteristics & Ordinary ROP & MRP & CTP \\
\hline Forecast & $\begin{array}{l}\text { Every item is forecasted indi- } \\
\text { vidually }\end{array}$ & $\begin{array}{l}\text { MPS is exploded to underlying } \\
\text { structural levels; demanded } \\
\text { quantities in a certain period of } \\
\text { time }\end{array}$ & $\begin{array}{l}\text { MPS is exploded to underlying } \\
\text { structural levels; but with } \\
\text { demand rates }\end{array}$ \\
\hline $\begin{array}{l}\text { Order trigger (for replen- } \\
\text { ishment) }\end{array}$ & $\begin{array}{l}\text { On hand inventory }+ \text { sch. } \\
\text { receipts }<\text { ROP }\end{array}$ & $\begin{array}{l}\text { Planned starting date of the } \\
\text { planned order }<\text { current time }+\end{array}$ & $\begin{array}{l}\text { Cover-time }<\text { lead time }+ \text { in- } \\
\text { spection time +buffer time }\end{array}$ \\
\hline & & $\Delta$ & $\begin{array}{l}\text { Projected on-hand inventory at } \\
\text { the end of the lead time }<0\end{array}$ \\
\hline Lead times & Fixed & $\begin{array}{l}\text { Fixed (but they can be short- } \\
\text { ened or prolonged heavily by } \\
\text { the rescheduling procedure) }\end{array}$ & Fixed \\
\hline Rescheduling (automatic) & No & $\begin{array}{l}\text { Yes, it is the base of the time } \\
\text { phasing technique }\end{array}$ & No \\
\hline Time phasing & Only open orders & $\begin{array}{l}\text { Open orders and planned } \\
\text { orders through the complete } \\
\text { planning horizon }\end{array}$ & Only open orders \\
\hline Forecasts (to suppliers) & No & Yes & $\begin{array}{l}\text { Yes (but approximately, } \\
\text { planned orders) }\end{array}$ \\
\hline Work load (forward visibility) & No & Yes & Yes \\
\hline $\begin{array}{l}\text { Planning Bill of material } \\
\text { (possible) }\end{array}$ & No & Yes & Yes \\
\hline ERP system (possible) & No & Yes & Yes \\
\hline
\end{tabular}

\section{ACKNOWLEDGMENTS}

Jan Wallander and Tom Hedelius Research foundation, project J01-23, has supported this study.

\section{REFERENCES}

[1] Orlicky J., 1975, Material Requirements Planning, McGraw-Hill, New York

[2] Vollman, T. E., Berry L. B., Whybark D. C., (1997), Manufacturing Planning and Control Systems (4 ed.), Irwin/McGraw-Hill

[3] Krajewski L. J., Ritzman L. P., 2005, Operations Management Strategy and Analysis (7 ed.), Prentice Hall

[4] Hopp W. J., Spearman M. L., 2001, Factory Physics: Foundations of Factory Management (2 ed), Irwin McGraw-Hill

[5] Vonderembse M. A., White G. P., 1996, Operations Management Concepts, Methods, and Strategies, West Publishing Company, Minneapolis/St.Paul

[6] Johnson H. T., Bröms A., 2000, Profit beyond measure, The Free Press

[7] Segerstedt A., 1991, Cover-Time Planning - An Alternative to MRP, PROFIL 10, Linköping

[8] Segerstedt A., 1998, Cover-Time Planning: A Less Complex Alternative to MRP, In: Drexl, A. and Kimms, A. (eds.), Beyond Manufacturing Resource Planning (MRP II) - Advanced Models and Methods for Production Planning, Berlin, Springer

[9] Jonsson P., 2000, Hur används egentligen materialplaneringsmetoder i svensk industri? (How are techniques for material control used in Swedish industry?; in Swedish), Bättre Produktivitet, $\mathrm{Nr}$ 4/2000, $14-17$

[10) Jonsson P., Mattsson S.-A., 2002, The selection and application of material planning method, Production Planning \& Control, Volume 13, Number 5 / July 01, 2002438 - 450

[11] St. John R. E., 1993, Material and Capacity Requirements Planning, Certification Review Course, American Production and Inventory Control Society 
[12] Spearman M. L., Woodruff D. L., Hopp W. J., 1989, A Hierarchical Control Architecture for Constant Work-in-Process (CONWIP) Production Systems, Journal of Manufacturing and Operations Management, 2, p. 141-171

[13] Spearman M. L., Zazanis M. A., 1992, Push and Pull Production Systems: Issues and Comparisons. Operations Research, 40, No. 3

[14] Segerstedt A., 2002, Production and Inventory Control at ABB Motors and Volvo Construction Equipment, Two Examples of MRP in Practical Use, Production Planning \& Control, 13, 317-325

[15] Jakobs F. R., Whybark D. C., 1999, Why ERP?, McGraw-Hill Higher Education

[16] Euwe M. J., Jansen P. A. L., Veldkamp C. T. H., 1998, The value of rescheduling functionality within standard MRP packages, Production Planning \& Control, Vol. 9, No. 4, 328-334

[17] Segerstedt A., 1995, Multi-Level Production and Inventory Control Problems - Related to MRP and Cover-Time Planning, PROFIL 13, Linköping 